\title{
DISCUSSION OF THE “HOTTEST YEAR ON RECORD” IN AUSTRALIA
}

\author{
Albert Parker ${ }^{1}$, Clifford D. Ollier ${ }^{2}$ \\ ${ }^{1}$ School of Engineering and Physical Science, James Cook University, Townsville, Australia \\ ${ }^{2} \mathrm{~S} c h o o l$ of Earth and Environment, The University of Western Australia, Crawley, Australia
}

Manuscript received: October 11, 2016

Revised version: February 03, 2017

Parker, A., Ollier, C.D., 2017. Discussion of the "hottest year on record" in Australia. Quaestiones Geographicae 36(1), Bogucki Wydawnictwo Naukowe, Poznań, pp. 79-91, 7 figs, 1 table.

ABSTRACT: The global temperature trends provided by the Australian Bureau of Meteorology are artificially exaggerated due to subjective and unidirectional adjustments of recorded values. The present paper aims to promote the use of the raw stations' data corrected only for urban heat island formation. The longer temperature records of Australia exhibit significant oscillations with a strong quasi-60 years' signature of downward phases 1880 to 1910, 1940 to 1970 and 2000 to present, and upwards phases 1910 to 1940 and 1970 to 2000. A longer oscillation with downward phase until 1910 and an upwards phase afterwards is also detected. The warming since 1910 occurred at a nearly constant rate. Over the full length of the long Australian records since the end of the 1800s, there is no sign of warming or increased occurrence of extreme events. The monthly highest and mean maximum temperatures do not exhibit any positive trend. The differences between monthly highest and lowest, or monthly mean maximum and mean minimum temperatures, are all reducing because of urban heat island formation.

KEY WORDS: tem perature warming, urban heat island, Australia, extreme events

Corresponding author: albert.parker.2014@gmail.com

\section{Introduction}

Raw temperature data of historical stations not affected by large urban heat islands show temperatures have not warmed since the end of the 1800s (Boretti 2013, Parker 2013a, b, Watts 2013, JoNova 2014, Parker 2014a, b, Parker, Ollier 2015a, b, c, Parker 2016, Marohasy 2017, WAclimate 2017). The list of the non-warming stations includes Alice Spring, Darwin, Cape Otway, Wilsons Promontory, Echuca, Horsham, Orbost, Gabo

Editors and Editorial Board are not responsible for the content of the paper and the personal views of the authors.
Island, Rutherglen, Newcastle, Bathurst, Burke, Amberley and Deniliquin and many others. In the case of historical stations with large urban heat islands, as for example Melbourne, Sydney, Perth, Adelaide and Brisbane the minimum temperatures have warmed significantly more than the maximum temperatures. The warming vanishes moving to the country side, as for example moving from Melbourne to Ballarat or other unaffected locations of regional Victoria as shown by Parker (2013b).

Technicalities such as the installation of Stevenson screens and more recently the installation of automatic weather stations using thermistors rather than mercury or alcohol thermometers 
affect the temperature readings for the average. Thermistors are much more sensitive to temperature changes and suggest larger fluctuations. Stevenson screens shield thermometer from direct heat radiation and may affect the maximum temperatures. Other factors affecting the temperature measurements include smaller urban heat island effect, change of land use, more localised effects linked to heat release and storage processes close to the thermometer location (such as the presence of an air conditioning unit, a car park, a glass tram stop or heavy traffic), and air motion due to buildings. Changes of location of the measuring equipment as Town to Airport or simple relocation of the thermometer will also affect the measurements.

The Australian Bureau of Meteorology (BOM) is well known for its continuous adjustments of the recorded values of temperatures to produce warming trends resembling those required to support the concept of global warming caused by anthropogenic carbon dioxide emission. The pinnacle of these administrative corrections has been the definition of the latest Australian Climate Observations Reference Network - Surface Air Temperature (ACORN-SAT) data set. This exercise has permitted the BOM to magnify the warming trends by reducing the temperatures of the past and to magnify the frequency of extreme events by increasing the summer temperatures while reducing the winter temperatures. The warming trend is computed from the time series of the average temperatures, the occurrence of extreme events is somehow linked to the time series of the difference between maximum and minimum temperatures. Reducing the temperatures of the past increases the warming, and increases the difference between maximum and minimum temperatures for same average temperature increases. Extreme events are become more frequent. The engineered warming has been shown in peer review papers (Boretti 2013, Parker 2013a, b, Parker 2014a, b, Parker, Ollier 2015a, b, c, Parker 2016) and blogs. The subtler differential seasonal warming has been shown so far only in the blog (JoNova 2014) in which Ken Stewart compared the ACORN and the Australian Water Availability Project (AWAP) temperature data set to find that Australian summer maximums have been warmed by $200 \%$ with the ACORN data.
Parker (2014b) presents the raw temperature data measured in Alice Spring and the latest ACORN reconstruction. Alice Spring is not considered in the present analysis. The time window end of the 1800s to present is actually covered not by one single station but by two stations, with a change of site from the Post Office to the Airport location. The significant overlapping in between the two records does not pose any issue in deriving a composite record as shown in Boretti (2013) and Parker (2014b). The reconstructed ACORN and the raw measured minimum and maximum temperatures do not agree. The time window of the reconstructed data magnifies the warming. The reconstructed data also increase the warming by making lower the temperatures of the past. The measured values show no warming at all since 1888, and a much smaller warming of 0.46 and $1.1^{\circ} \mathrm{C} /$ century of minimum and maximum temperatures since 1910. Legitimate homogenizations of the Alice Spring record are not easy, as there are no surrounding stations to average with. The supporting data of Parker (2014b) were downloaded from Australian Government Bureau of Meteorology (BOM 2014a, b). Climate Data Online (CDO) provides access to a range of statistics, recent weather observations and climate data from the Australian Data Archive for Meteorology (ADAM), a database which holds weather observations dating back to the mid1800s for some sites. The climate change trends computed by the Bureau of Meteorology are based on selected subsets of data that have been changed many times in the recent years with raw temperature measurements mostly arbitrarily corrected or neglected. Analysis of the raw temperature data has always returned patterns completely different from those claimed by the BOM in their state-of-the-climate reports.

Kenskingdom (2014) presents the mysterious correction for Rutherglen, a rare long rural temperature record where measurements had come from the same place since 1913. Rutherglen was one of the temperature recording stations that was subject to large adjustments which turned a slight cooling trend into a strongly warming one. The official notes showed that the site did not move and was a continuous record. Retired scientists who worked at times at Rutherglen confirm the official thermometer had not moved. The original cooling trend of $-0.35^{\circ} \mathrm{C} /$ century 
was transformed into a $+1.73^{\circ} \mathrm{C} /$ century warming after homogenization justified by the $\mathrm{BOM}$ as the result of an unrecorded shift.

JoNova (2014) presents the result of the analysis performed by Ken Stewart of the adjustments used to create the all-new ACORN dataset compared with the other BOM dataset called AWAP. Since summer maxima are the ones used to generate the most headlines in Australia, the trend in average summer maximums has been tripled by adjustments. Ken Stewart splits the data into months, and compares the trends in maxima in the AWAP and ACORN datasets, across the entire nation. Most of the adjustments happen to data from the hottest months of the year, October to March. Even though the measured maxima in February and March are possibly cooler now than they were in the early 1900s, they have been adjusted to show warming trends. Adjustments grossly exaggerate monthly and seasonal warming. The supporting data was downloaded from Australian Government Bureau of Meteorology (BOM 2014b, c).

Watts (2013) presents Australian summer (December to February) surface air temperatures over the satellite era. This time the source of information is not a BOM data set but the Remote Sensing Systems (RSS 2017) and University of Alabama in Huntsville (UAH) data base. Microwave sounding unit temperature measurements have been obtained from the troposphere since 1979, when they were included within the National Oceanic and Atmospheric Administration (NOAA) weather satellites. Satellites measure radiances in various wavelength bands, which is then mathematically processed to obtain indirect inferences of temperature. Different groups analysed the satellite data. Among these groups are RSS and UAH. The Australian temperatures from the RSS and UAH groups show that there was nothing unusual about the 2012 summer. The supporting data were downloaded from KNMI (2014).

Parker, Ollier (2015b) asked the question which causes more warming, carbon dioxide or Bureau of Meteorology (BOM) adjustments? and concluded the warming of Australia is mostly an artefact of BOM adjustments. Another fundamental research question was which causes more summer heatwaves: carbon dioxide or Bureau of Meteorology (BOM) adjustments? The answer by Ken Stewart was that the heat waves of Australia are likewise mostly an artefact of BOM adjustments.

The present paper shows that the use of raw data provides a superior estimate of the actual warming trends than the unnaturally exaggerated global temperature trends provided by the Australian Bureau of Meteorology. This superior estimate shows the repeated claims that almost every year is the hottest year on record are not trustworthy. The warming in the world top net sequestering country for carbon dioxide, Australia (Parker, Ollier 2015d) is conclusively substantially overrated.

\section{Data and methods}

The conclusions of Parker, Ollier (2015b) and Ken Stewart are further supported here by the analysis of the time series recorded in the 30 stations of longest record included in the BOM list of long temperature records (BOM 2009). The supporting data were downloaded from Australian Government Bureau of Meteorology (BOM 2014a).

Considering the presence of a quasi-60 years' oscillation in the climate with upwards phases 1910-1940 and 1970-2000 and downward phases 1880 to 1910, 1940 to 1970 and 2000 to present (Parker 2013b), a proper assessment of the warming trends requires 60 or even better 120 years of data collected without any perturbing event. The oscillations up to the quasi-60 years are superimposed on a trend with downward phase (1880 to 1910) and upward phase (1910 to present) that may be a longer term oscillation (Parker 2013b). The warming claimed to start in 1970 actually started in 1910.

The warming trend is computed by linear fitting. If an experimental distribution $\left\{x_{j}, y_{j}\right\} j=1, \ldots$, $\mathrm{m}$ represents the $\mathrm{m}$ monthly average temperature observations $y_{j}$ at the time $x_{i}$, the classic estimation of the time rate of change is based on the linear fitting:

$$
y^{+}(x)=\left(y_{0}^{+}+a^{+} \times x\right)
$$

where:

$y^{+}$- the temperature,

$x$ - the time, and

$y_{0}^{+}, a^{+}$- the fitting coefficients

$a^{+}$- linear warming rate. 
To study the influence of the multi-decadal oscillations, the fitting with a line and sines of expression:

$$
y^{*}(x)=\left(y_{0}^{*}+a^{*} \cdot x\right)+\sum_{i=1}^{n}\left[A_{i} \cdot \sin \left(\pi \cdot \frac{x-x_{c, i}}{w_{i}}\right)\right]
$$

where:

$y^{*}$ - the temperature,

$x$ - the time,

$n$ - the number of sines, and

$y_{0}{ }^{*}, a^{*}, A_{i}, x_{c, i}, w_{i}$ - the fitting coefficients may be used,

$a^{*}$ - linear warming rate, and

$A_{i^{\prime}} x_{c, i^{\prime}} w_{i}$ - the amplitudes, phases and periods of the oscillations.

\section{Results}

Figure 1 presents the temperatures in Cape Otway Lighthouse:

- monthly values of average maximum and average minimum with 36 months' average and linear trends;

- monthly highest and lowest values with 36 months' average and linear trends;

- 36 months' average and linear trends of monthly average maximum and minimum, highest and lowest.

There is no sign of warming or increasing occurrences of extreme events. The Cape Otway (1864 to 2014) trends in $\left[{ }^{\circ} \mathrm{C} /\right.$ year] are: highest -0.0084 , mean maximum -0.0148 , mean minimum 0.0065 , and lowest 0.0058 . Cape Otway is significantly cooling over the time window in the highest and mean maximum temperatures less affected by modified heat storage and heat release processes around the thermometer location. The much smaller warming of the mean minimum and lowest temperatures is mostly due to extremely low values (outliers) measured in the mid-1860s. Starting in 1870, trends for mean minimum and lowest temperatures further reduces to 0.0038 and $0.0037^{\circ} \mathrm{C} /$ year respectively. Similarly, significantly reducing are the differences between highest and lowest temperatures or mean maximum and mean minimum temperatures.

Considering that what makes headlines in Australia is the daily maximum temperature, it may be interesting to compare the daily maximum temperatures truly measured which can be obtained from Australian Government Bureau of Meteorology (BOM 2014a) with the manipulated ACORN data which can be downloaded from Australian Government Bureau of Meteorology (BOM 2014d).

Figure 2 presents a comparison of truly measured and ACORN manipulated daily maximum temperatures in Cape Otway Lighthouse:

- all the years of data;

- 1910 to present. A significant cooling is transformed into a significant warming by neglect-
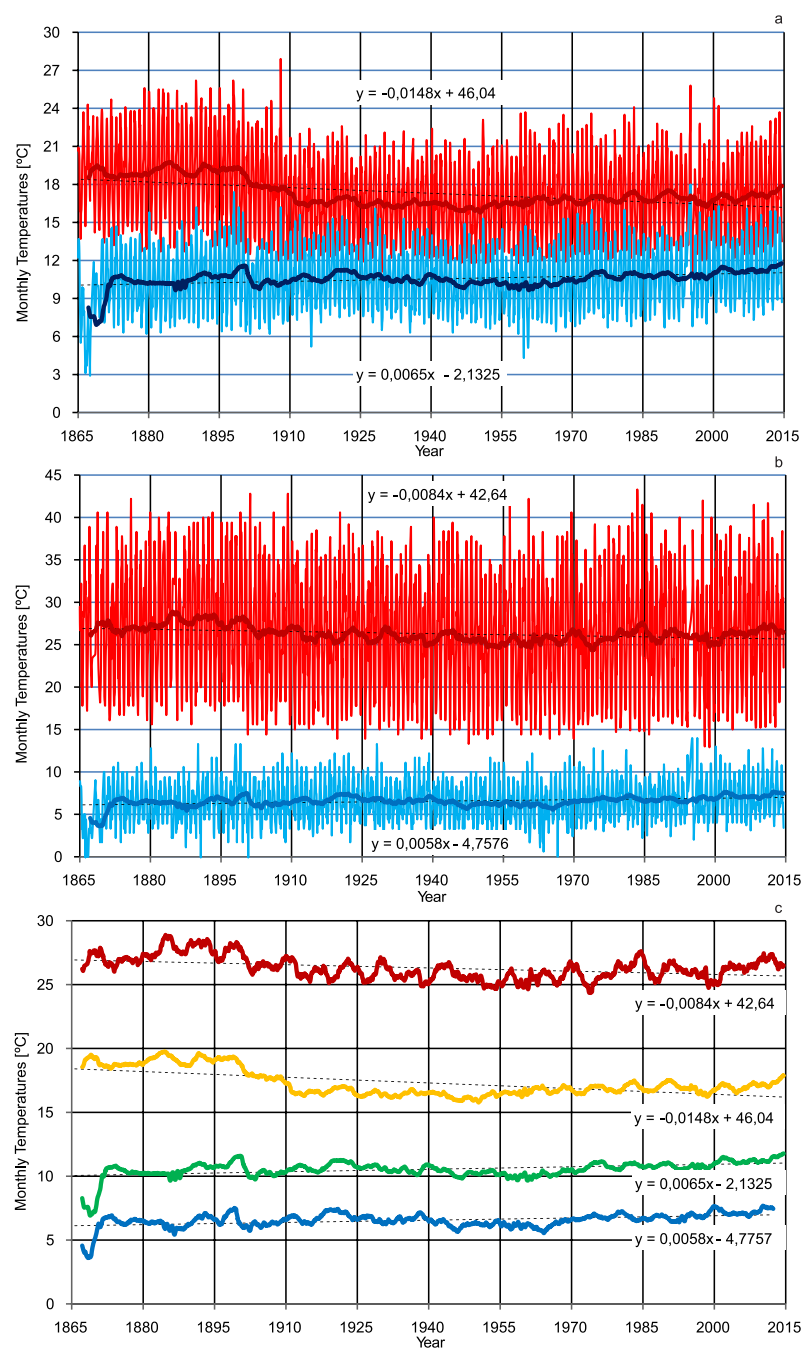

Fig. 1. Temperatures in Cape Otway Lighthouse: a) monthly values of average maximum and average minimum with 36 months average and linear trends; b) monthly highest and lowest values with 36 months average and linear trends; c) 36 months average and linear trends of monthly average maximum and minimum, highest and lowest. Data from Australian Government Bureau of Meteorology (BOM 2014a) accessed October 10, 2014. 
ing the data collected prior of 1910 which do not help the 'highest on record' claim, plus massaging the data 1910 to present by reducing past temperatures and so almost double the warming.

The massaging for Cape Otway Lighthouse is not as huge as other stations such as Rutherglen but is still substantial.

Figure 3 presents another analysis of the temperatures at Cape Otway Lighthouse:

- measured monthly average maximum temperatures month-by-month;

- measured monthly highest month-by-month;

- yearly average of daily maximum temperatures.

The year 2013 is not the year with the largest monthly average maximum temperature - that was 1908, nor the year with the highest absolute temperature recorded - that was 1982. The year average of the maximum temperature of the year 2013 was not the largest on record, as there were another 38 years in between 1870 and 1902 where the average of the daily maximum temperatures was larger than in 2013 , even $2.29^{\circ} \mathrm{C}$.
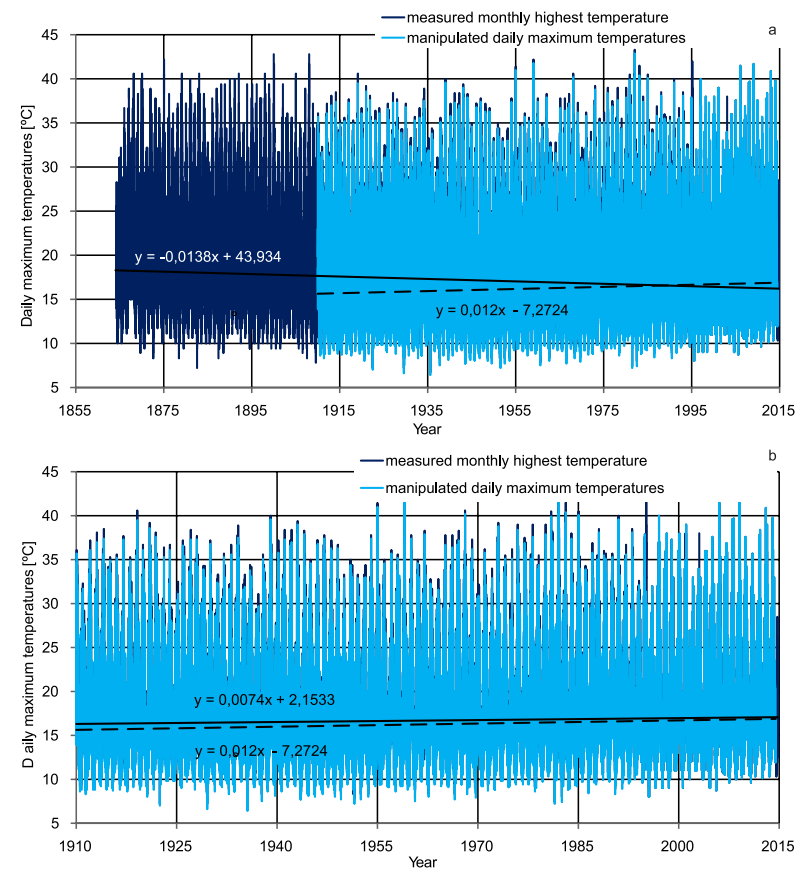

Fig. 2. Comparison of truly measured and ACORN manipulated daily maximum temperatures in Cape Otway Lighthouse: a) all the years of data; b) 1910 to present. Data from Australian Government Bureau of Meteorology (BOM 2014a, d) accessed October 10, 2014.
Figure 4 presents one more analysis of the temperatures in Cape Otway Lighthouse:

- measured monthly average maximum and results obtained by a fitting with a line and sines with 36 months' average trends;

- time rate of change of the monthly average maximum measured and fitted as a function of time;

- time rate of change of the monthly average maximum measured and fitted as a function of the record length.

The perfectly oscillating model describes the measured pattern well. The temperatures are oscillating, with a quasi-60 years' oscillation of upwards phases up to 1880,1910 to 1940 and 1970
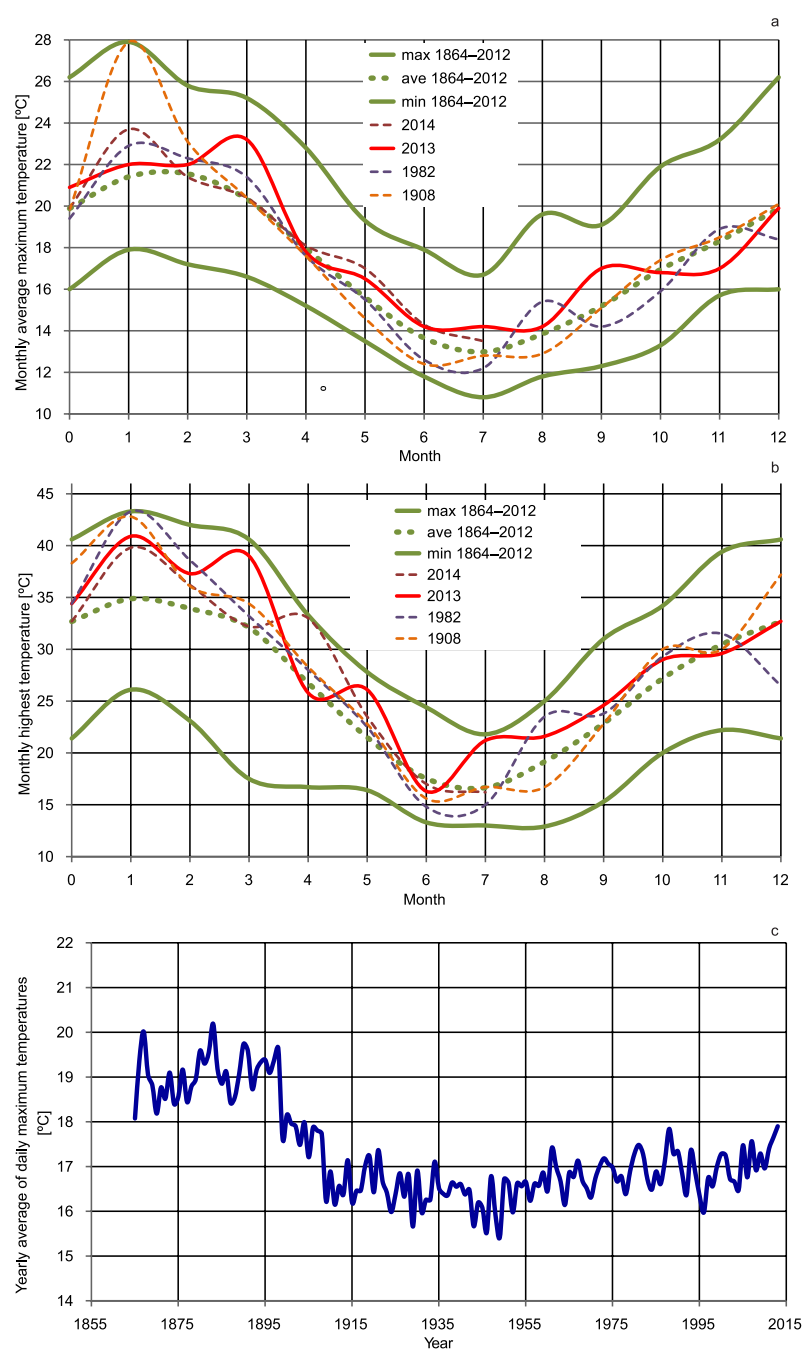

Fig. 3. Temperatures in Cape Otway Lighthouse:

a) measured monthly average maximum temperatures month-by-month; b) measured monthly highest month-by- month; c) yearly average of daily maximum temperatures. Data from Australian.

Government Bureau of Meteorology (BOM 2014a) accessed October 10, 2014. 
to 2000 and downward phases 1880 to 1910,1940 to 1970 , and 2000 to present. The model indicates the presence of a longer term oscillation with downward phase up to 1910 and upward phase afterwards that appears also in the reconstructions of global temperatures (Parker 2013b).

The analyses of Figures 1-4 produce the same conclusion, namely that there has been not too much warming since the 1800s and not too much increase of extreme events. The present warming is very probably natural or mostly natural as it started in 1910. The same conclusions may be
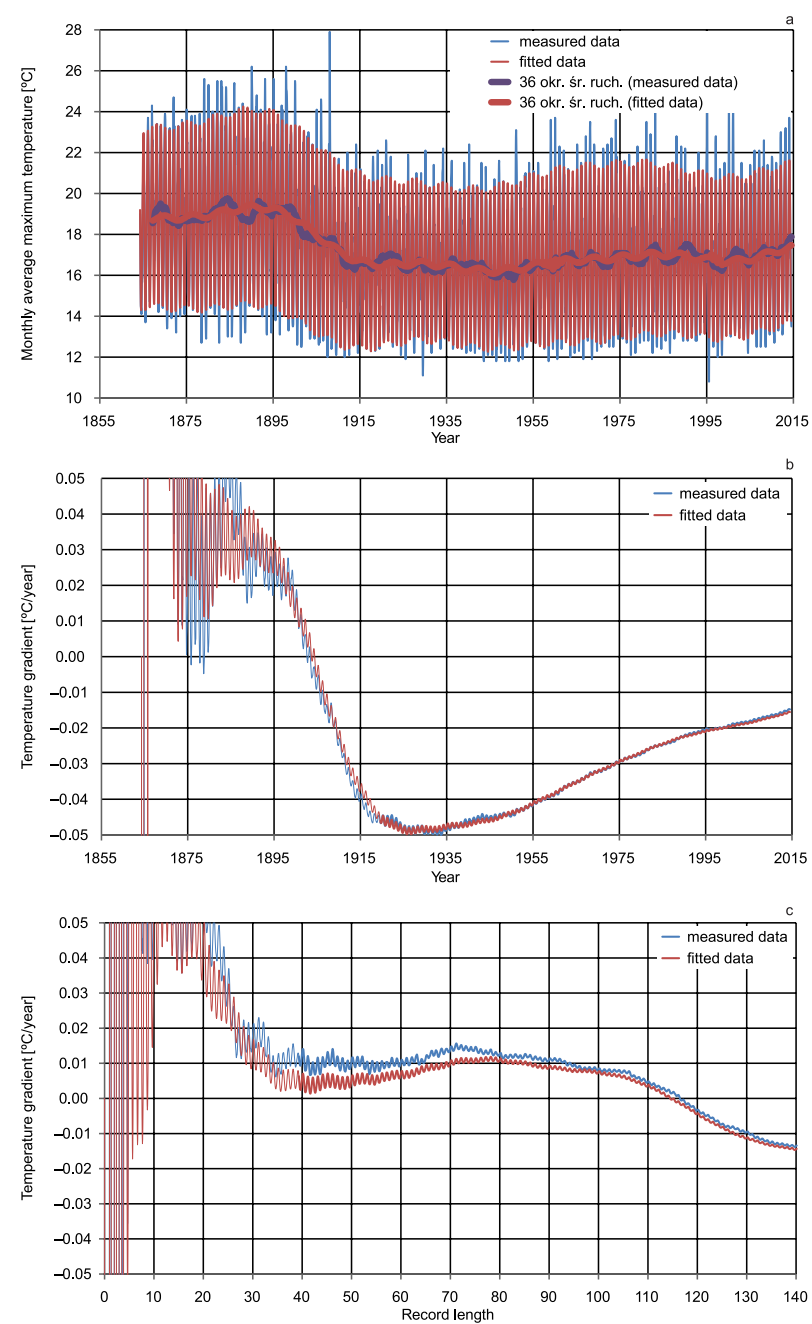

Fig. 4. Temperatures in Cape Otway Lighthouse: a) measured monthly average maximum and results obtained by a fitting with a line and sines with 36 months average trends; $b$ ) time rate of change of the monthly average maximum measured and fitted as a function of time; c) time rate of change of the monthly average maximum measured and fitted as a function of the record length. Data from Australian Government Bureau of Meteorology (BOM 2014a) accessed October 10, 2014. drawn from the data for most of the 30 locations considered, with remarkable differences only in case of the capital cities where the build-up of large heat islands produces an increased warming rate at the same time as this build-up. The oscillatory pattern of Figure 4 is also presented by the reconstructions of global temperatures as the NASA Goddard Institute for Space Studies (GISS) Surface Temperature (Hansen et al. 2010, GISTEMP Team 2017).

Figure 5 presents an analysis of the monthly mean GISS 1200 T2m/SST global temperature
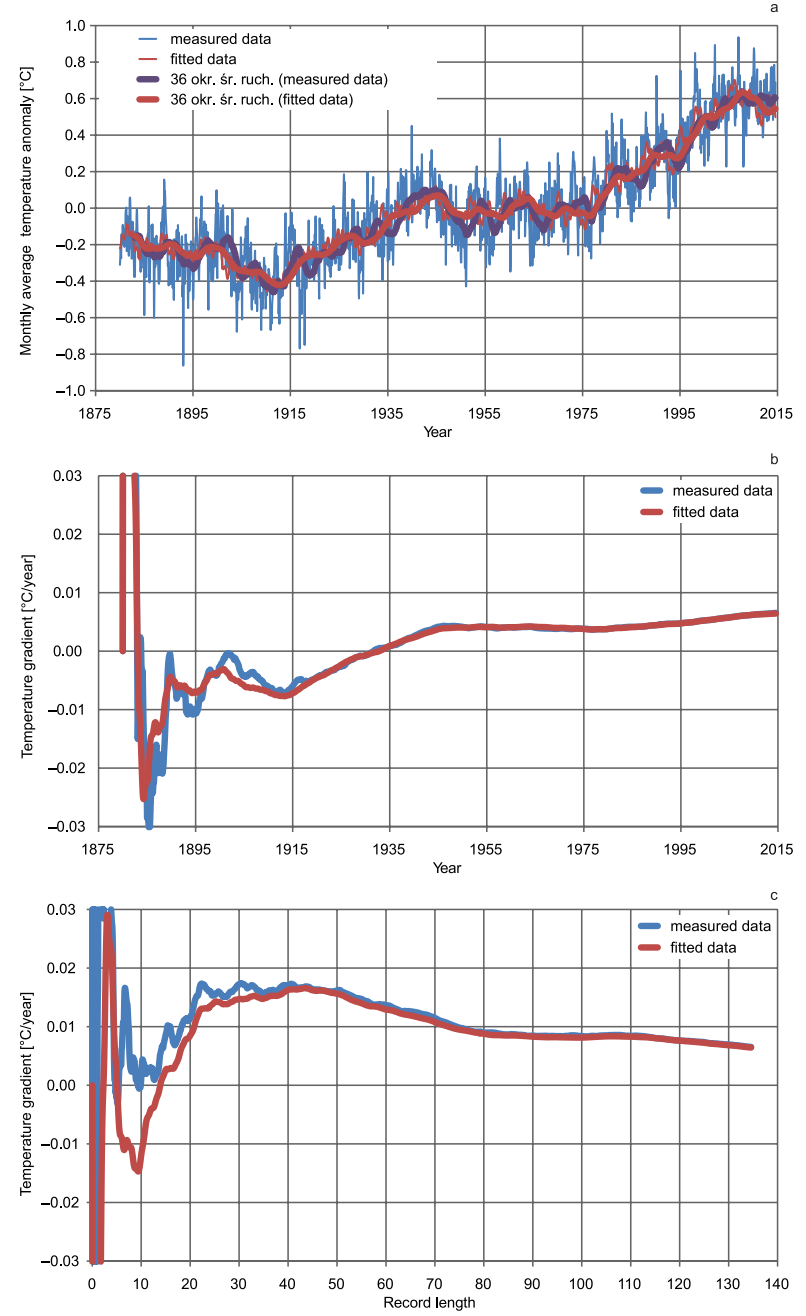

Fig. 5. Analysis of the monthly mean GISS 1200 T2m/SST global temperature anomaly index:

a) reconstructed monthly mean and results obtained by a fitting with a line and sines with 36 months

average trends; b) time rate of change of the monthly mean measured and fitted as a function of time; c) time rate of change of the monthly mean measured and fitted as a function of the record length. Data from KNMI (2014) accessed October 12, 2014. 
anomaly index (Hansen et al. 2010, GISTEMP Team 2017):

- reconstructed monthly mean and results obtained by a fitting with a line and sines with 36 months' average trends;

- time rate of change of the monthly mean measured and fitted as a function of time;

- time rate of change of the monthly mean measured and fitted as a function of the record length.

Data from KNMI (2014) downloaded on October 12, 2014.
The perfectly oscillating model well describes the measured pattern. The temperatures are oscillating, with a quasi-60 years' oscillation of upwards phases up to 1880, 1910 to 1940 and 1970 to 2000 and downward phases 1880 to 1910,1940 to 1970 , and 2000 to present. The model indicates the presence of a longer term oscillation with downward phase up to 1910 and upward phase afterwards. The global warming trend starts in 1910 and not in 1970 and it is therefore natural rather than driven by anthropogenic carbon dioxide emission.

Table 1. Warming trend for the 30 longest temperature records of Australia having data collected in a single location, with measurements started before 1900 and ended after 1985. Data from Australian Government Bureau of Meteorology (BOM 2014a) accessed October 10, 2014.

\begin{tabular}{|c|c|c|c|c|c|c|c|c|c|}
\hline \multicolumn{5}{|c|}{ Station data } & \multicolumn{4}{|c|}{ Temperature trends $\left[{ }^{\circ} \mathrm{C} /\right.$ year $]$} & \multirow[b]{2}{*}{ Notes } \\
\hline Station name & $\begin{array}{l}\text { Sta- } \\
\text { tion } \\
\text { No. }\end{array}$ & $\begin{array}{l}\text { Start } \\
\text { year }\end{array}$ & $\begin{array}{l}\text { Last } \\
\text { year }\end{array}$ & $\begin{array}{c}\text { Years } \\
\text { of } \\
\text { data }\end{array}$ & $\begin{array}{c}\text { Mean } \\
\text { Max }\end{array}$ & $\begin{array}{l}\text { Mean } \\
\text { Min }\end{array}$ & $\begin{array}{l}\text { High- } \\
\text { est }\end{array}$ & Lowest & \\
\hline Bathurst Gaol & 63004 & 1858 & 1983 & 126 & -0.0158 & 0.0078 & -0.0129 & 0.0033 & \\
\hline Boulia Airport & 38003 & 1888 & 2014 & 127 & 0.0027 & 0.0151 & -0.0006 & 0.0179 & \\
\hline Bourke Post Office & 48013 & 1871 & 1996 & 126 & -0.0092 & 0.0054 & -0.0143 & 0.0062 & \\
\hline Brisbane Regional Office & 40214 & 1887 & 1986 & 100 & 0.0000 & 0.0157 & -0.0014 & 0.0209 & \\
\hline Bundaberg Post Office & 39015 & 1892 & 1990 & 99 & -0.0050 & 0.0143 & -0.0033 & 0.0249 & \\
\hline Burdekin Shire Council & 33001 & 1892 & 1986 & 95 & 0.0036 & 0.0154 & 0.0029 & 0.0355 & \\
\hline Burketown Post Office & 29004 & 1890 & 2009 & 120 & 0.0079 & 0.0111 & 0.0041 & 0.0160 & \\
\hline Cape Otway Lighthouse & 90015 & 1864 & 2014 & 151 & -0.0148 & 0.0065 & -0.0084 & 0.0058 & \\
\hline Charters Towers Post Office & 34002 & 1893 & 1992 & 100 & 0.0002 & 0.0095 & -0.0007 & 0.0074 & \\
\hline Dalby Post Office & 41023 & 1893 & 1992 & 100 & -0.0084 & 0.0098 & -0.0086 & 0.0161 & \\
\hline Deniliquin (Wilkinson St) & 74128 & 1858 & 2003 & 146 & -0.0173 & 0.0124 & -0.0165 & 0.0089 & \\
\hline Echuca Aerodrome & 80015 & 1858 & 2014 & 157 & 0.0005 & -0.0063 & & & $\begin{array}{l}\text { highest/lowest } \\
\text { since } 1957\end{array}$ \\
\hline Forbes (Camp Street) & 65016 & 1873 & 1998 & 126 & 0.0031 & 0.0082 & 0.0295 & -0.0079 & \\
\hline Gabo Island Lighthouse & 84016 & 1877 & 2014 & 138 & -0.0019 & 0.0076 & & & $\begin{array}{l}\text { highest/lowest } \\
\text { since } 1957\end{array}$ \\
\hline Gayndah Post Office & 39039 & 1893 & 2009 & 117 & 0.0009 & 0.0191 & -0.0026 & 0.0245 & \\
\hline Goondiwindi Post Office & 41038 & 1891 & 1991 & 101 & -0.0025 & 0.0136 & -0.0065 & 0.0192 & \\
\hline Gunnedah Pool & 55023 & 1876 & 2011 & 136 & -0.0140 & 0.0108 & -0.0162 & 0.0081 & \\
\hline Hobart (Ellerslie Road) & 94029 & 1882 & 2014 & 133 & 0.0059 & 0.0087 & 0.0081 & 0.0090 & \\
\hline Inverell Comparison & 56017 & 1874 & 1997 & 124 & 0.0108 & -0.0029 & 0.0144 & -0.0071 & \\
\hline Low Head (Comparison) & 91057 & 1895 & 2001 & 107 & 0.0182 & 0.0087 & 0.0273 & 0.0115 & \\
\hline Melbourne Regional Office & 86071 & 1855 & 2014 & 160 & 0.0070 & 0.0151 & 0.0038 & 0.0187 & \\
\hline Nhill & 78031 & 1897 & 2008 & 112 & 0.0009 & -0.0033 & 0.0026 & -0.0077 & \\
\hline Perth Regional Office & 9034 & 1897 & 1992 & 96 & 0.0161 & 0.0162 & 0.0179 & 0.0194 & \\
\hline Port Lincoln & 18070 & 1892 & 2002 & 111 & 0.0037 & 0.0143 & 0.0024 & 0.0241 & \\
\hline Richmond Post Office & 30045 & 1893 & 2014 & 122 & 0.0013 & 0.0133 & -0.0005 & 0.0155 & \\
\hline Robe Comparison & 26026 & 1884 & 2014 & 131 & 0.0057 & 0.0072 & 0.0002 & 0.0051 & \\
\hline Sydney (Observatory Hill) & 66062 & 1859 & 2014 & 156 & 0.0125 & 0.0097 & 0.0138 & 0.0097 & \\
\hline Tewantin Post Office & 40264 & 1895 & 1996 & 102 & -0.0020 & 0.0308 & 0.0051 & 0.0375 & \\
\hline Walgett Council Depot & 52026 & 1878 & 1993 & 116 & 0.0054 & 0.0041 & 0.0073 & 0.0060 & \\
\hline Wilsons Promontory Lighthouse & 85096 & 1872 & 2014 & 143 & -0.0022 & 0.0112 & & & $\begin{array}{l}\text { highest/lowest } \\
\text { since } 1957\end{array}$ \\
\hline \multicolumn{5}{|l|}{ average values } & 0.0004 & 0.0103 & 0.0017 & 0.0129 & \\
\hline
\end{tabular}


The global reconstructions as GISS (Hansen et al. 2010, GISTEMP Team 2017) are artificially biased upwards to reproduce the carbon dioxide emission trend, as shown by Parker (2013a), but the strong natural oscillation signal prevails. The very likely overrated warming rate since 1880 is $0.00654^{\circ} \mathrm{C} /$ year or $0.654^{\circ} \mathrm{C} /$ century. This rate increases to $0.00851^{\circ} \mathrm{C} /$ year or $0.851^{\circ} \mathrm{C} /$ century by considering the data only since 1910 . The warming rate cleared of the oscillations is about constant since the 1940s.

Table 1 presents the warming trend for the 30 longest temperature records of Australia collected in a single location, with measurements started before 1900 and continued until after 1985 .

The maximum temperature is less affected by the heat release and heat transfer processes about the thermometer location and it is the parameter to consider when assessing if there is any warming. In the 30 locations, the monthly mean maximum temperature is warming $0.0004^{\circ} \mathrm{C} /$ year, or $0.04^{\circ} \mathrm{C} /$ century. That means there is no change within the limits of accuracy of the measurements. The monthly mean minimum temperature is warming $0.0103^{\circ} \mathrm{C} /$ year, or $1.03^{\circ} \mathrm{C} /$ century. Similar trends are shown by the monthly highest and monthly lowest, warming $0.0017^{\circ} \mathrm{C} /$ year or $0.17^{\circ} \mathrm{C} /$ century and $0.0129^{\circ} \mathrm{C} /$ year or $1.29^{\circ} \mathrm{C} /$ century respectively, with highest temperatures warming one order of magnitude less than the lowest.

From the worldwide data, Figure 5, temperatures are subject to multi-decadal oscillations with a very clear periodicity of quasi-60 years having downward phases 1880 to 1910, 1940 to 1970 and 2000 to present, and a possible longer term oscillation of downward phase up to 1910 and upward phase afterwards. Because the GISS temperature record is biased upwards, as many supporting stations have upwards biased temperatures rather than the actual thermometer reading, the Byrd station in Antarctica or Alice Spring in Australia just to name a few, the magnitude of the warming that is occurring since 1910 is difficult to assess, but it is certainly less than the $0.00851^{\circ} \mathrm{C} /$ year or $0.851^{\circ} \mathrm{C} /$ century of the GISS signal 1910 to present.

The limited data available suggest phasing of quasi-60 years' and longer term oscillation of periodicity quasi-120 years. Computing linear trends starting in a valley of the peaks \& valleys oscillation as 1910 or 1970 is only a trick to overrate the warming trend. With time windows shorter or longer the warming rate reduces considerably. Over the last 10-15 years the warming is very close to zero.

From the long term Australian data, Figure 1-4 - examples and Table 1 - summary, the Australian temperatures follow pretty much the same oscillations as the global temperatures. Because the temperature records are more likely biased upwards than downward by the heat release and heat storage processes about the thermometer location embedded in the urbanization strong especially for the minimum temperatures, the magnitude of the warming that is occurring since 1910 is difficult to assess. However, if we do consider the maximum temperature as the indicator, it is certainly much less than the $0.00851^{\circ} \mathrm{C} /$ year or $0.851^{\circ} \mathrm{C} /$ century of the GISS global signal 1910 to present. The data since the start of the record in the late 1800s show no warming at all.

Without being very selective on the time window, and without manipulating the thermometer reading to reduce the temperatures of the past or increasing the differences between summer and winter values for the present by arbitrary correction, over the full time of the record there is no sign of warming or increased extreme events for the Australian long term stations.

\section{Discussion}

It is certainly possible to find few papers in the peer reviewed literature that supports the BOM homogenization process (Trewin 2013, Ashcroft et al. 2014, Ayers 2016, Davis, Hanna 2016). There are also papers that criticize this process (Boretti 2013, Parker 2013, 2014a, b, Parker 2016). They cannot be all right. What is important is to look at the measurements and apply the scientific method. As there is no way to perform a better measurement going back in the past, there is no legitimate way to correct recorded data of the past. Therefore, we should stick to the raw data. A definitive statement about the $\mathrm{BOM}$ procedure is provided by Parker (2016).

The Global Historical Climatology Network (GHCN) v2 temperature time series (GISS Surface Temperature Analysis, 2012) in Alice Spring and all the 36 other stations located in a circle of 1,000 
$\mathrm{km}$ from Alice Spring do not show any warming. There are stations covering different time windows having very close patterns of temperatures. In this circle of $3,141,593 \mathrm{~km}^{2}$ (roughly $50 \%$ of Australia) that is mostly underdeveloped, none of the stations supposed to support the $+2^{\circ} \mathrm{C}$ warming per century - Australia's largest warming rate - claimed by BOM actually has a warming trend. Figure 2 of Parker (2016) presents the area of concern and the individual temperature time series for the 37 stations within the $1,000 \mathrm{~km}$ circle (images from GISS Surface Temperature Analysis, 2012). It is therefore only an artefact by $\mathrm{BOM}$ to produce the warming. Homogenization is supposed to be used to account for upwards biases such as Urban Heat Island, not to introduce upwards biases. As noticed by Parker (2015a), the ACORN adjustments of Australian temperatures are in the wrong direction, inevitably in the direction to produce a warming much larger than the legitimate.

In the centre of Australia, all the stations available in a circle of radius $1,000 \mathrm{~km}$ were showing very little or no warming, as still acknowledged in the GHCN v2 data set up to October 2011 (Fig. 6). To move from a scattered population of stations with unequal time coverage and many missing data but both uniformly not warming to produce the largest warming trend for Australia as depicted by the BOM it only requires many administrative corrections and the development of an ad-hoc procedure to compute spatial trends. The analysis of the temperatures for the area at the centre of Australia proposed by Mearns (2015) and Parker (2016). As noticed by Humlum (2017), as the past does not change, any record undergoing continuing changes cannot describe the past correctly all the time. Humlum operates with three quality classes for global temperature records, with quality class 1 representing the highest quality level, the satellite records (UAH and RSS); quality class 2 - the HadCRUT surface record; and quality class 3 - the NCDC and GISS surface records. As the past should not change continuously, the latest BOM ACORN data set and the further computations done to derive the warming trend maps qualify well above quality class 3 for Humlum's standards.

The above analysis permits to assess if the claims almost every year of the hottest year on record are trustworthy. In case for example of the Australia's extremes of 2013, our conclusions are completely opposed to the views of the researchers of the Australian Research Council Centre of Excellence for Climate System Science (ARCCSS) who computed the influence of global warming on Australia's climate. Their alleged "fingerprints of climate change" referred to the Australia's extremes of 2013 are wrong. According to a chief investigator of the centre (UNSW School of Biological, Earth and Environmental Sciences, 2014) we often talk about the fingerprint of human-caused climate change when we look at extreme weather patterns but if we were climate detectives, then Australia's hottest year on records in 2013 wasn't just a smudged fingerprint at the scene of the crime, it was a clear and unequivocal handprint showing the impact of human-caused global warming. According to the researchers of the centre, January 7 was the hottest day on record, January 2013 was the hottest month on record, December-February 2013 was the hottest summer on record, September-November 2013 was the hottest spring on record, 2013 was the hottest year on record, and there are extreme summer events and drought in Eastern Australia.

Apart from the exaggerations, they link every climate event to anthropogenic carbon dioxide emission, without proof. The method they use involves the suppression of observations that do not support the theory of anthropogenic global warming, and manipulating real data to manufacture increasing temperatures and increasing extreme events.

We should also consider the role of the Bureau of Meteorology. The climate trend maps compiled by Bureau of Meteorology in their climate change section are completely unreliable, as the alleged increasing temperature is obtained by lowering temperatures of the past by "adjustments". The longest of the Australian temperature records that were considered the most reliable by Bureau of Meteorology on February 2009 (BOM 2009) are still available as raw temperatures in the climate data online section and consistently show no warming and no increased extreme events within the limit of accuracy of measurements. Figure 7 shows the air temperatures global, northern and southern hemisphere since 1979 from satellite observations. The warming trend since 1979 is not exactly global, as it is the northern hemisphere to warm at a rate of $1.8^{\circ} \mathrm{C} /$ century, while the southern hemisphere is only warming $0.9^{\circ} \mathrm{C} /$ 

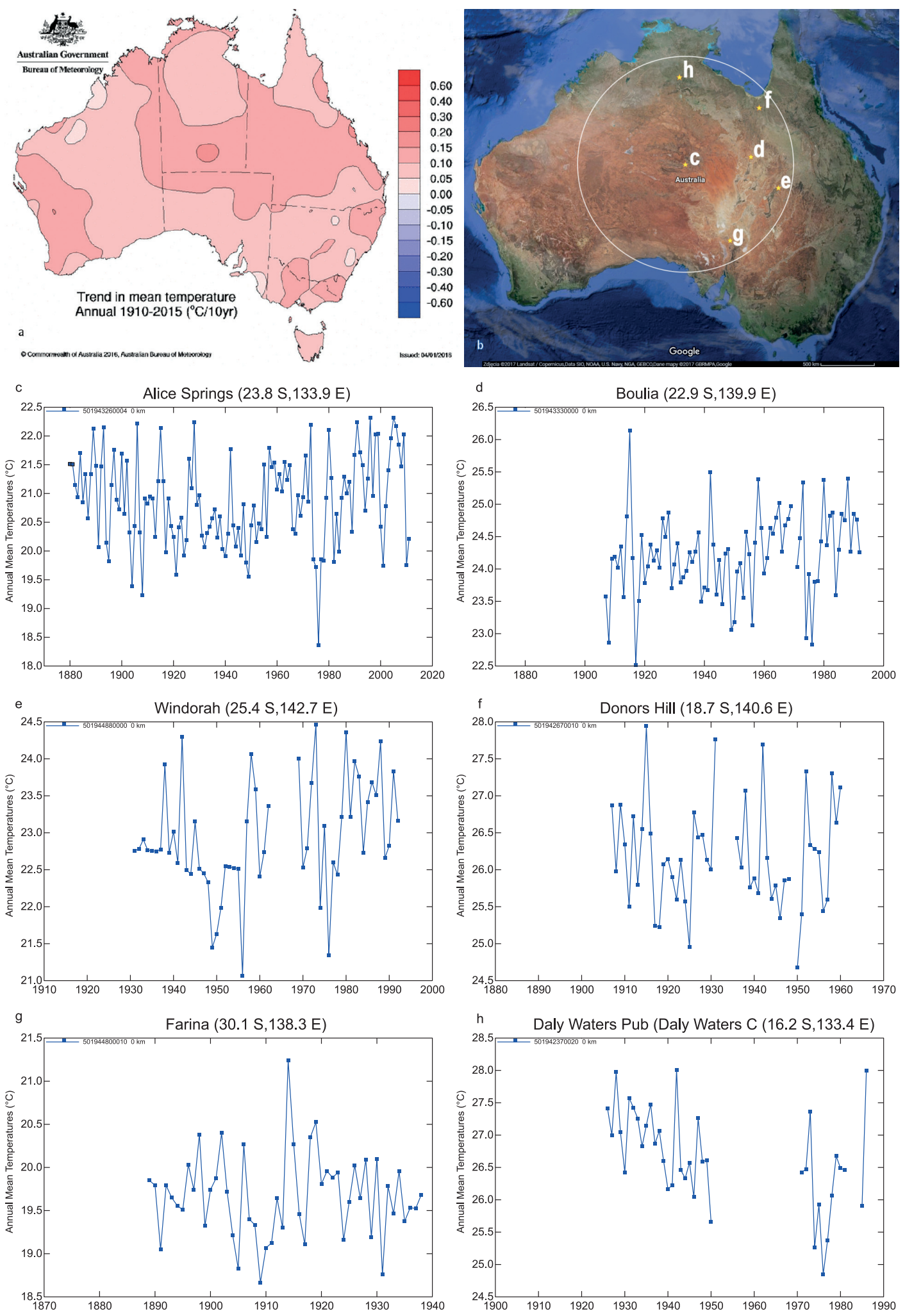

Fig. 6. a - Latest trend map 1910 to present by the Australian Government Bureau of Meteorology. (BOM 2017). The BOM suggest that at the center of Australia, around Alice Spring, there is a warming of up to $2{ }^{\circ} \mathrm{C} /$ century. $\mathrm{b}$ - the actually non-warming center of Australia within the radius of 1,000 km circle as still acknowledged in the Global Historical Climatology Network (GHCN) v.2 of October 2011. Some of selected individual temperature time series for the 37 stations within the Central Australia - the longest - are from GISS Surface Temperature Analysis (2017a): c - Alice Springs, d - Boulia, e - Windorah, f - Donors Hill, g - Farina, h - Daly Waters Pub. The BOM trend map is incompatible with the already massaged individual records of the GHCN v.2 (cf. Parker 2016). 
century. As the time window includes more years of the positive rather than the negative phase of the multi-decadal oscillations, the actual warming rate is indeed quite small for the less developed southern hemisphere and possibly motivated by the Urban Heat Island and change of land use in addition to sun activity than affected by the carbon dioxide emissions.
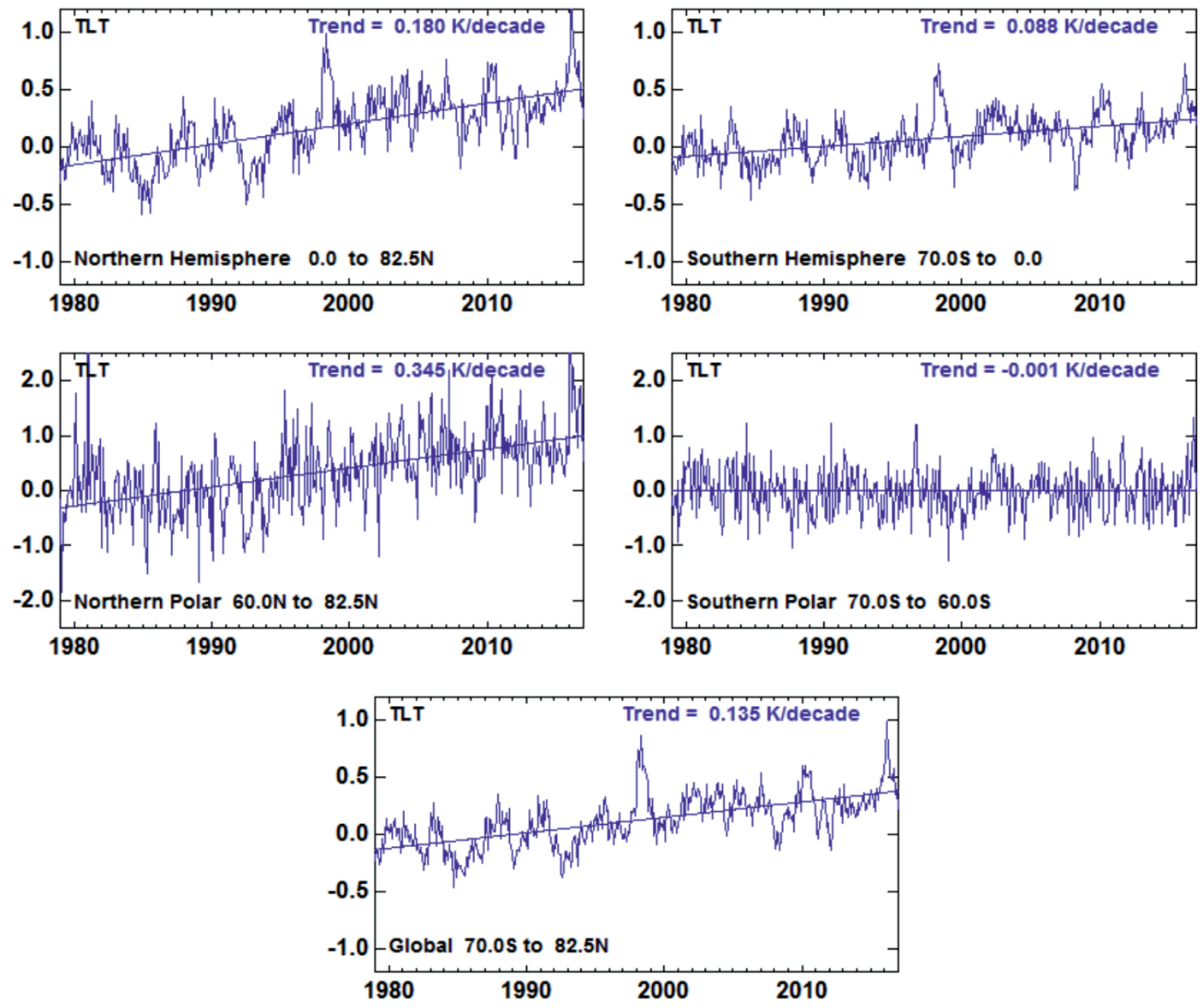

MSU/AMSU Channel TLT Brightness Temperature Trend (1979-2016)

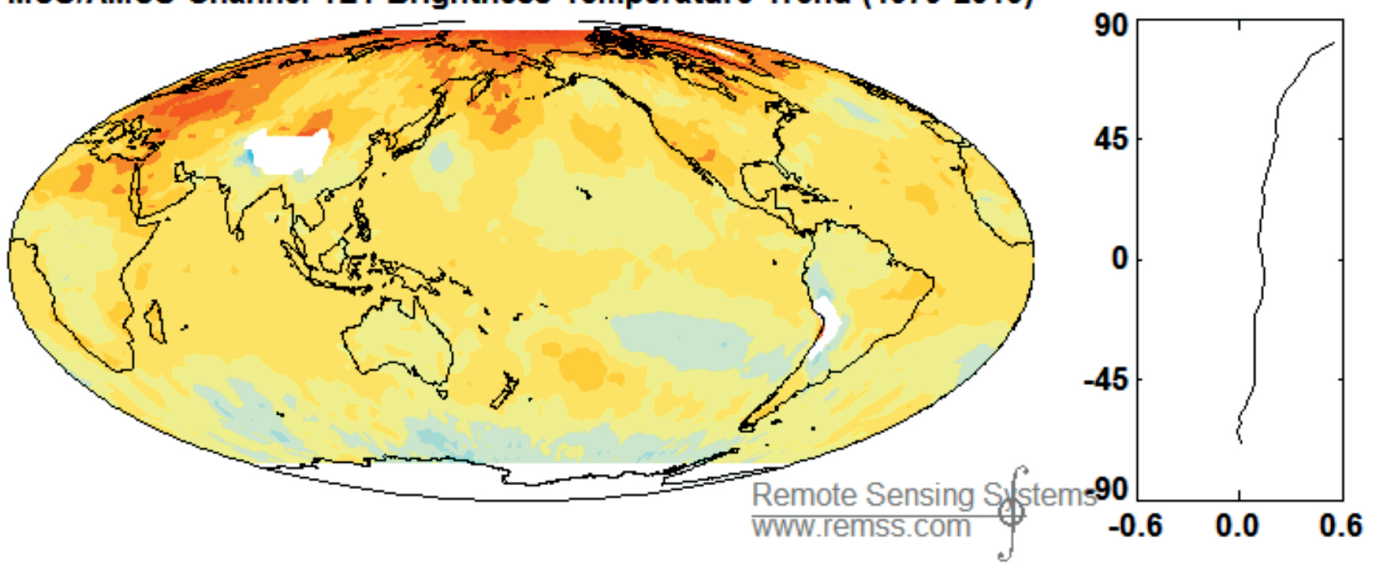

Brightness Temperature Trend (K/decade)

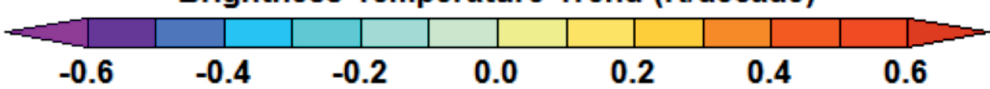

Fig. 7. Satellite temperatures since 1979 (global, northern and southern hemisphere, northern and southern polar). Images from RSS (2017). Warming of northern and southern hemispheres is different. 


\section{Conclusion}

We suggest that priority should be given to real observed data, and data analysis should use standard statistical techniques. On this basis we find that over the full time since records were collected there is no appreciable sign of warming or increase in extreme events in Australia. There is no cause for alarm if the normal scientific method of observation - hypothesis - testing is retained. Revising the raw temperature data of the past is an unscientific process that lies somewhere between dubious and fraudulent. Any link between the Australian temperature data and carbon dioxide emission is utterly speculative.

\section{References}

Ashcroft L., Karoly D.J., Gergis J., 2014. Southeastern Australian climate variability 1860-2009: a multivariate analysis. International Journal of Climatology 34(6): 1928-1944.

Ayers G.P., 2016. Australia's Air Temperature Trend Reviewed. Journal of Southern Hemisphere Earth Systems Science 66(3): 270-280.

Boretti A., 2013. Statistical analysis of the temperature records for the Northern Territory of Aaustralia. Theoretical and Applied Climatology 114(3): 567-573.

BOM [Bureau of Meteorology], 2009. Australian stations measuring maximum air temperature; more than $50 \mathrm{y}$ of data and $80 \%$ complete record; Produced: 12 February 2009. Online: www.bom.gov.au/climate/how/long_T_ sites.csv (accessed October 10, 2014).

BOM [Bureau of Meteorology], 2014a. Climate Data Online (CDO). Online: www.bom.gov.au/climate/data/ (accessed October 10, 2014).

BOM [Bureau of Meteorology], 2014b. ACORN-SAT. Online: www.bom.gov.au/climate/change/acorn-sat/ (accessed October 10, 2014).

BOM [Bureau of Meteorology], 2014c. Australian Water Availability Project (AWAP). Online: www.bom.gov.au/ jsp/awap/ (accessed October 10, 2014).

BOM [Bureau of Meteorology], 2014d. ACORN-SAT daily temperatures. Online: www.bom.gov.au/climate/ change/acorn/sat/data/acorn.sat.maxT.090015.daily. txt (accessed October 10, 2014).

BOM [Bureau of Meteorology], 2017. Australian climate variability \& change - Trend maps. Online: http://www. bom.gov.au/climate/change/index.shtml\#tabs=Tracker\&tracker=trend-maps (accessed February 23, 2017).

Davis C.J., Hanna E.G., 2016. Temperature and rainfall trends in northern Australia 1911-2013: implications for human activity and regional development. Climate Research 71(1): 1-16.

GISS Surface Temperature Analysis, 2017a. Station Data Based on GHCN v2, Ending in Oct 2011. Online: data. giss.nasa.gov/gistemp/station_data_v2 (accessed February 23,2017$)$.
GISS Surface Temperature Analysis, 2017b. Station Data Based on GHCN v3. Online: data.giss.nasa.gov/gistemp/stdata/ (accessed February 23, 2017).

GISTEMP Team, 2017. GISS Surface Temperature Analysis (GISTEMP). NASA Goddard Institute for Space Studies. Online: data.giss.nasa.gov/gistemp/ (accessed January 31, 2017).

Hansen J., Ruedy R., Sato M., Lo K., 2010. Global surface temperature change. Reviews of Geophysics 48 RG4004: 1-29. doi:10.1029/2010RG000345.

Humlum O., 2017. Global temperatures; An overview to get things into perspective. Climate4you. Online: www.climate4you.com (accessed February 23, 2017).

JoNova, 2014. Australian summer maximums warmed by 200. Online: joannenova.com.au/2014/10/australiansummer-maximums-warmed-by-200/ (accessed October 10, 2014)

Kenskingdom, 2014. Rutherglen: Spot the Outlier. Online: kenskingdom.word press.com/2014/09/02/rutherglen-spot-the-outlier/ (accessed October 10, 2014).

KNMI [Koninklijk Nederlands Meteorologisch Instituut], 2014. Climate Explorer. Online: climexp.knmi.nl/ (accessed October 10, 2014).

Marohasy J., 2017. Blog. Online: jennifermarohasy.com/ (accessed January 31, 2017).

Mearns E., 2015. Temperature adjustments in Australia. Climate Etc. Online: judithcurry.com/2015/03/17/temperature-adjustments-in-australia (accessed September 12, 2016).

Parker A., 2013a. Why global warming went missing since the year 2000. Nonlinear Engineering 2(3-4):129-135.

Parker A., 2013b. Melbourne urban heat island contamination of temperature trend maps in Victoria, Australia. Nonlinear Engineering 2(1-2): 39-62.

Parker A., 2014a. Present contributions to sea level rise by thermal expansion and ice melting and implication on coastal management. Ocean and Coastal Management 98: 202-211.

Parker A., 2014b. The temperature record of Alice Spring, Northern Territory of Australia revisited. Environmental Science: An Indian Journal 10(3):81-87.

Parker A., 2015a. The ACORN Adjustments of Australian temperatures are in the wrong direction. Physical Science International Journal 6(4): 245-252.

Parker A., 2015b. The artefacts of data biases in surface temperatures are certain only to hide the hiatus., American Journal of Geophysics, Geochemistry and Geosystems 1(3): 66-70.

Parker A., 2016. Australian temperature measurements disprove engineered products. New Concepts in Global Tectonics Journal 4(4): 693-698.

Parker A., Ollier C.D., 2015a. Deliberate misrepresentation of the rainfall patterns of Australia: There are no rainfall reductions in Australia caused by the globally increasing anthropogenic carbon dioxide emission. Environmental Science: An Indian Journal 10(10): 376-383.

Parker A., Ollier C.D., 2015b. The warming of Australia is man-made, but not by carbon dioxide. Environmental Science: An Indian Journal 10(5): 172-183.

Parker A., Ollier C.D., 2015c. Unreliability of global temperature trends: the circular logic of comparing models with models or with models inspired reconstructions to circumvent lack of validation versus actual measurements. Nonlinear Engineering 4(4): 249-259. 
Parker A., Ollier C.D., 2015d. Carbon dioxide flux measurements based on satellite observations differ considerably from the consensus values. Energy \& Environment 26(3): 457-463.

RSS [Remote Sensing Systems], 2017. MSU \& AMSU Time Series Trend. Online: images.remss.com $/ \mathrm{msu} / \mathrm{msu}_{-}$ time_series.html (accessed February 2, 2017).

Trewin B., 2013. A daily homogenized temperature data set for Australia. International Journal of Climatology 33(6): 1510-1529.

UNSW School of Biological, Earth and Environmental Sciences, 2014. Handprint of human-caused climate change in Australia. Online: www.bees.unsw.edu.au/ handprint-human-caused-climate-change-australia (accessed October 10, 2014).

WAclimate, 2017. Average temperature trends across Western Australia. Online: waclimate.net/ (accessed January 31, 2017).

Watts A., 2013. Claim humans play role in Australia's angry hot summer. Online: wattsupwiththat.com/2013/06/27/ claim-humans-play-role-in-australias-angry-hot-summer/ (accessed October 10, 2014). 